\title{
COMPARISON BETWEEN 2D TRANSVAGINAL ULTRASONOGRAPHY AND HYSTEROSCOPY IN DETECTION OF INTRAUTERINE PATHOLOGY IN PATIENTS WITH INFERTILITY
}

\author{
By
Ahmed Khalil Abd El-Shafi, Ismail Talaat El-Garhy, Maged Mohamed Labeb* and Ahmed Osama Abd El-Motaal \\ Department of Obstetrics and Gynecology, Faculty of Medicine, Al-Azhar University \\ Department of Obstetrics and Gynecology*, Consultant of Obstetrics and Gynecology in \\ Military Hospitals \\ Corresponding author: Ahmed Khalil Abd El-Shafi, \\ E-mail: drahmedkhali191@gmail.com
}

\begin{abstract}
Background: Submucous fibroid, endometrial polyps, congenital uterine abnormalities and intrauterine adhesions are all potential causes of infertility. Distortion of uterine cavity by a fibroid or a septum can lead to implantation failure and recurrent early miscarriage. Traditionally, transvaginal ultrasound (TVUS) has been the first-line diagnostic tool for evaluating uterine diseases, also considering that gynecologists are familiar with the technique since it is included in the basic training in obstetrics and gynecology. Certainly, TVUS is an easy, fast and cheap method widely used.
\end{abstract}

Objective: To evaluate the accuracy of 2D transvaginal ultrasonography (TVS) compared with hysteroscopy in diagnosis of intrauterine pathology in infertile women.

Patients and Methods: This comparative prospective cohort study included 160 infertile women who had undergone transvaginal ultrasonography (TVS) compared with hysteroscopy in diagnosis of intrauterine pathology. The study was conducted at Ghamra Military Hospital. Cases were included in the study during the period between February 2018 and Jun 2021. All candidates included on the study underwent transvaginal ultrasonography using a Voluson 730 machine, and diagnostic hysteroscopy was done postmenstrual. TVS and diagnostic hysteroscopy were carried out during the same cycle.

Results: TVS had a misdiagnosis in 18 cases at rate of $11.25 \%$. Ten patients have endometrial polyps, three have submucous fibroid, three were intrauterine adhesions, and two septate uterus.

Conclusion: Diagnostic hysteroscopy was superior to two-dimensional TVS in the diagnosis of intrauterine pathology. Diagnostic hysteroscopy gave more informations than traditional two-dimensional TVS ultrasound. Hysteroscopy not only provided accurate visual assessment of the uterine cavity, but also provided a chance to treat any pathology detected during the examination.

Keywords: Transvaginal ultrasound, Endomterial thickness, intrauterine lesions, Hysteroscopy.

\section{INTRODUCTION}

The uterus is an important part in the female reproductive system as it plays a role in sperm migration, embryo implantation, and fetal nourishment. Congenital uterine anomalies, acquired uterine lesions, and systemic diseases may affect such uterine functions including 
successful pregnancy (Elizabeth and Viaor, 2012).

Intrauterine pathologies were found in $11-40 \%$ of infertile patients. Therefore, exclusion of intrauterine pathology is an important step before starting ART and treatment of any discovered lesion may improve ART outcome (El Tagy et al., 2018).

Submucous fibroid, endometrial polyps, congenital uterine abnormalities and intrauterine adhesions are all potential causes of infertility. Distortion of uterine cavity by a fibroid or a septum can lead to implantation failure and recurrent early miscarriage (Gupta et al., 2016).

Evaluation of the uterine cavity is an important part of the gynecological check, especially in symptomatic women and, over the last few decades, a number of technical and technological advancements have allowed a superb investigation of this organ. Traditionally, transvaginal ultrasound (TVUS) has been the first-line diagnostic tool for evaluating uterine diseases, also considering that gynecologists are familiar with the technique since it is included in the basic training in obstetrics and gynecology. Certainly, TVUS is an easy, fast and cheap method widely used. For a long time, hysteroscopy was considered exclusively as a "second level" test, in relation to its greater invasiveness comparing with TVUS, needing hospitalization, general anesthesia, and an operating room as a setting (Di Spiezio et al., 2016).

TVS is readily available and cost effective and non-invasive, therefore it is universally preferred as the initial diagnostic procedure for evaluating uterine structural pathologies. We conclude that TVS as a routine procedure before hysteroscopy enables the detection of the details of most localized endometrial lesion (Niknejadi et al., 2012).

Hysteroscopy can be regarded as the gold standard for the evaluation of the uterine cavity and subsequent detection of intrauterine pathology. It is a safe and simple procedure and can be carried out successfully in an outpatient setting without anesthesia (Nouri et al., 2010).

Hysteroscopy not only provides accurate visual assessment of the uterine cavity, but also provides a chance to treat any pathology detected during the examination. The availability of hysteroscopy with a smaller diameter has made the use of outpatient or office hysteroscopy feasible as a routine examination (Kandeel et al., 2020).

The characteristic of "direct view" of the hysteroscopy represents a huge benefit compared with the TVUS approach in uterine cavity evaluation and it can ensure a very high diagnostic sensitivity and specificity. In this sense, TVUS should be considered a "screening test" that could define only the suspicion of the presence of an intrauterine pathology. Often, in fact, this sonographic diagnosis is nonspecific, inaccurate on number, type and size of the disease, offering vague/probable diagnosis, not certainties (Di Spiezio et al., 2016).

Hysteroscopy, however, is considered a gold-standard technique for uterine cavity examination, since it allows direct visualization of potential lesions and can be paired with biopsy if necessary. Nevertheless, this procedure is invasive 


\section{COMPARISON BETWEEN 2D TRANSVAGINAL ULTRASONOGRAPHY...}

and often requires anesthesia and specialized equipment (ie, a hysteroscope). Moreover, hysteroscopy is more costly than HSG or SHG and does not provide information about the external morphology of the organ, myometrium, or adnexa. Transvaginal sonography (TVS) is a simple, painless, and cost-effective examination that is capable of providing accurate information about IULs and is not associated with adverse pregnancy outcomes. However, studies of the diagnostic accuracy of TVS have produced conflicting results (Hajishaiha et al., 2011).

The main problem with hysteroscopy is that it is an invasive procedure. It is not yet clear whether the findings of hysteroscopy in infertile couples increase pregnancy rates. But we believe that there is high rate of infertility because of intrauterine pathology most commonly intrauterine adhesions and inflamed endometrium and as these pathologies affect fertility of women, and can be easily treated, hysteroscopy should be performed routinely in order to make a diagnosis and early treatment. This could improve the reproductive future of the patient (El Tagy et al., 2018).

The aim of this comparative study was to evaluate the accuracy of $2 \mathrm{D}$ transvaginal ultrasonography (TVS) compared to hysteroscopy in diagnosis of intrauterine pathology in infertile women.

\section{PATIENTS AND METHODS}

This comparative prospective cohort study included 160 infertile women who had undergone transvaginal ultrasonography (TVS) compared with hysteroscopy in diagnosis of intrauterine pathology. The study was conducted at Ghamra Military Hospital. Cases were included in the study during the period between February 2018 and June 2021.

Patients were about study characteristics, and those agreeing to participate, gave informed consents. The study was approved by the hospital's ethical committee.

Inclusion criteria: Patients having infertility age group (20-40 years) with normal levels of $\mathrm{FSH}, \mathrm{LH}$ and prolactin hormones and normal semen analysis of their husbands or who had unexplained infertility, and patients have no medical problems.

Exclusion criteria: Patients with age less than 20 years or more than 40 years, bleeding suspected or confirmed pregnancy, history suggestive of active infection like history of abnormal vaginal discharge, and couples with male factor infertility (abnormal semen parameters and /or sexual dysfunctions).

All eligible patients were submitted to detailed history from each patient with special reference to present, past, menstrual and obstetric histories, and general, abdominal, and pelvic examination (Including; bimanual assessment of the uterine size, position, mobility and adnexal evaluation). The cervix was inspected for signs of cervicitis. Testing for urinary HCG (all patients should have negative results). TVS was done for all candidates in the early follicular phase $\left(2^{\text {nd }}\right.$ or $3^{\text {rd }}$ day) when menstrual bleeding stopped and before the diagnostic hysteroscopy. Diagnostic hysteroscopy was done postmenstrual. TVS and diagnostic hysteroscopy were carried out during the same cycle. 


\section{Technique of transvaginal sonography:}

All patients underwent transvaginal ultrasonography using a Voluson 730 machine produced by General Electric Company with a vaginal probe using 5-9 $\mathrm{MHz}$ transducer serial number A44896.

The patient was asked to evacuate the bladder before examination. Examination was performed in the supine position with the knees flexed and the lower limbs abducted. The probe was introduced into the vagina covered with a condom filled and covered with echo gel.

The uterine anatomy and the adnexae were visualized using a $7.5 \mathrm{MHz}$ vaginal probe transducer. The uterine cavity was evaluated in the long axis from the fundus to the cervix (sagittal view), then the probe was turned slowly anticlockwise to visualize the transverse view of uterus. During the examination, the uterine cavity was meticulously observed by sliding, rotating, and tilting the transvaginal scanhead. The contour of the endometrial stripe was assessed in the midline sagittal plane and the point of maximum thickness of the stripe (ET) was measured on a frozen image at $1.5 \times$ magnification. Appearance of the endometrial stripe was commented upon as either normal or abnormal. A specific note was made of any focal lesion seen in terms of impression of an endometrial polyp, submucous fibroid, intramural fibroid.

\section{Technique of diagnostic hysteroscopy:}

- Hysteroscopic examination was done for all cases using rigid panoramic type with a continuous irrigation and suction sheath $(25 \mathrm{~cm}$ in length, $4 \mathrm{~mm}$ in diameter) with an outer sheath of $5.5 \mathrm{~mm}$ and a 30-degree fore-oblique lens (Circon Acmi, Germany). The light source used was a metal halide automatic source (Circon Acmi, G61A Germany) with 150 watt lamp. A fiberoptic cable was connected to light source and to hysteroscopy. The technique used to provide constant uterine distention. 0.9 percent saline solution was used as distension media insufflated at atmospheric pressure (two bags connected by a urological "Y" outflow and located 1.5 meter above the patient). By doing a flow of $150-200 \mathrm{ml} / \mathrm{min}$ with a resulting endouterine pressure of around 40 $\mathrm{mmHg}$, were obtained which created no problems. An accurate assessment of the calculated deficit was be made. This was done by measuring the volume infused and subtracting the volume recovered giving the presumed volume absorbed by the patient. If the deficit exceeds $2000 \mathrm{ml}$ then the procedure should be abandoned unless it is nearly complete.

\section{Documentation and hysteroscopy:}

- Hysteroscopic findings were documented clearly and accurately by including photographic evidence from video recording. The woman's details and clinical history were recorded, including information on menstrual history, indication for referral, and any relevant medical history and medication.

- Procedure details including anesthesia, the cervical canal dilated, a tenaculum placed, and which hysteroscope and distention medium were used should all be documented.

- Hysteroscopic findings incorporating the overall appearance and vasculature 


\section{COMPARISON BETWEEN 2D TRANSVAGINAL ULTRASONOGRAPHY...}

of the cervical canal, endometrial cavity, and tubal ostia were documented.

- The presence or absence of any polyps, fibroids, or suspicious endometrium and whether or not an endometrial biopsy was obtained and recorded. Any complications of the procedure (eg, failure to obtain access to the uterine cavity) were noted. Finally, details of a management and treatment plan were determined after discussion with the patient.

\begin{abstract}
Statistical Analysis:
The collected data were tabulated and analyzed using SPSS version 16 software (SPSS Inc, Chicago, ILL Company). Categorical data were presented as number and percentages while quantitative data were expressed as mean and standard deviation. Chi square test, student " $t$ " test and ANOVA were used as tests of significance. ROC curve was used to detect validity $\&$ predictivity of vaginal US and hysteroscopy in diagnosis of postmenopausal bleeding. The accepted level of significance in this work was stated at 0.05 ( $\mathrm{P}<0.05$ was considered significant).
\end{abstract}

\section{RESULTS}

Table (1): Patients characteristics and indication for examination $(n=160)$

\begin{tabular}{|c|c|}
\hline Variable & \\
\hline Age mean SD years (range) & $27.18+-5.72(20-40)$ \\
\hline Duration of infertility mean+- SD years(range) & $6+3.4$ years \\
\hline Infertility: & $80 \%(128)$ \\
Primary NO (\%) & $\mathbf{2 0} \%(32)$ \\
Secondary NO (\%) & $80 \%(128)$ \\
Indication: & $13.7 \%(22)$ \\
As a part of infertility workup & $6.25 \%(10)$ \\
Before ART & \\
After > 1 failed IVF cycles &
\end{tabular}

There were 128 patients included during infertility workup, another 22 patients included before ART and ten patients were included after failed more than trial of ART (Table 2).

Table (2): Finding of TVS and hysteroscopy $(n=160)$

\begin{tabular}{|c|c|c|c|}
\hline Variables & TVS & Hysteroscopy & P Value \\
\hline Normal study & $121(75.6 \%)$ & $103(64.4 \%)$ & 0.022 \\
\hline Endometrial polyp & $19(11.9 \%)$ & $29(18.2 \%)$ & 0.117 \\
\hline Submucous fibroid & $14(8 \%)$ & $17(10.6 \%)$ & 0.571 \\
\hline Septate uterus & $3(1.9 \%)$ & $5(3.12 \%)$ & 0.0434 \\
\hline Intrauterine adhesions & $3(1.9 \%)$ & $6(3.8 \%)$ & 0.340 \\
\hline
\end{tabular}


Normal hysteroscopic findings were in $65 \%$ and abnormal finding could be detected in $35 \%$ women. Hysteroscopy was found to have better sensitivity (95.12\%) and NPV (90.47\%) than TVS which were $78.21 \%$ and $48.41 \%$ respectively. TVS showed that 39 cases $(24.37 \%)$ had intrauterine pathology predominantly fibroids, polyps via hysteroscopy 57 patients $(35.6 \%)$ were diagnosed. The most frequent findings being endometrial polyps.

Table (3): Sensitivity, specificity, predictive values and total accuracy of 2D TVS and Hysteroscopy for individual uterine anomalies

\begin{tabular}{|c|c|c|c|}
\hline \multicolumn{2}{|c|}{ Procedure } & 2D TVS & Hysteroscopy \\
\hline \multirow{3}{*}{$\begin{array}{c}\text { Myomas (\%) } \\
\text { (Submucous) }\end{array}$} & Sensitivity & 81.4 & 89.5 \\
\cline { 2 - 4 } & Specificity & 94.3 & 100 \\
\cline { 2 - 4 } & PPV & 80 & 100 \\
\cline { 2 - 4 } & NPV & 90 & 98.3 \\
\hline & Accuracy & 91.6 & 94.7 \\
\hline \multirow{4}{*}{ Polyp (\%) } & Sensitivity & 73.3 & 84.4 \\
\cline { 2 - 4 } & Specificity & 89.8 & 100 \\
\cline { 2 - 4 } & PPV & 70.3 & 100 \\
\cline { 2 - 4 } & NPV & 84.2 & 87.5 \\
\cline { 2 - 4 } & Accuracy & 82 & 92.2 \\
\hline \multirow{4}{*}{ Intrauterine } & Sensitivity & 50 & $66.7 \%$ \\
\cline { 2 - 4 } & Specificity & $100 \%$ & $100 \%$ \\
\cline { 2 - 4 } & PPV & $100 \%$ & $100 \%$ \\
\cline { 2 - 4 } & NPV & $86.1 \%$ & $91.2 \%$ \\
\cline { 2 - 4 } & Accuracy & $87.5 \%$ & $92.5 \%$ \\
\hline
\end{tabular}

TVS had $100 \%$ specificity and PPV which was nearly comparable to hysteroscopy i.e. $90 \%$ and $97.8 \%$. TVS had a misdiagnosis in 18 cases rate of $11.25 \%$. Ten patients were endometrial polyps, three were submucous fibroid, three were intrauterine adhesions and two

\section{DISCUSSION}

In the present study, normal hysteroscopic findings were in $65 \%$ and abnormal finding could be detected in $35 \%$ women. Hysteroscopy was found to have better sensitivity $(95.12 \%)$ and NPV (90.47\%) than TVS which were $78.21 \%$ and $48.41 \%$ respectively. TVS had $100 \%$ specificity and PPV which was nearly comparable to hysteroscopy i.e. $90 \%$ and $97.8 \%$. were septate uterus. Overall, as a test for the detection of intra-uterine abnormalities, TVS had $79 \%$ sensitivity and $82 \%$ specificity, $84 \%$ positive predictive value and $71 \%$ negative predictive value in comparison with hysteroscopy.

Overall, as a test for the detection of intra-uterine abnormalities, TVS had $79 \%$ sensitivity and $82 \%$ specificity, $84 \%$ positive predictive value and $71 \%$ negative predictive value in comparison with hysteroscopy.

Soares et al. (2010) and Loverro et al. (2011) have reported that TVS had a sensitivity and specificity of as high as (75-85\%) and (90-100\%), respectively for the detection of endometrial polyps. Using 


\section{COMPARISON BETWEEN 2D TRANSVAGINAL ULTRASONOGRAPHY...}

hysteroscopy as a gold standard, TVS showed excellent specificity (91.2\%), good sensitivity $(88.2 \%)$, an $81.4 \%$ PPV and a $94.6 \%$.

Results of hysteroscopy in present study were almost similar to that of $\mathrm{Kim}$ and Rhim (2014) results of TVS in present study are nearly similar to study of Kulsum et al. (2010) with a lower sensitivity $78 \%$ and NPV $47.6 \%$.

Our study reported that TVS had a misdiagnosis in 18 cases rate of $11.25 \%$. Ten patients were endometrial polyps, three were submucous fibroid, three were intrauterine adhesions and two were septate uterus. According to Niknejadi et al. (2012) TVS showed excellent specificity (91.2\%), good sensitivity (88.2\%), 81.4\% PPV, and a 94.6\% NPV in uterine polyp detection, while Niknejadi et al. (2012) reported that TVS had a misdiagnosis rate of $4.2 \%$ and was, therefore, less effective in distinguishing polyps than hysteroscopy.

In our cases of endometrial fibroids, TVS had a sensitivity of $89.2 \%$ and a specificity of $99.6 \%$. These findings correlated with the result of Loverro et al. (2011) in which TVS had a $90.9 \%$ sensitivity and a $100 \%$ specificity for the detection of endometrial fibroids.

In our study, TVS failed to distinguish adhesions in 3 out of 6 patients (50\%). Shalev et al. (2010) reported a high accuracy of TVS in diagnosing uterine adhesions. It is recommended that in case of endometrial adhesion detected by sonography, the final diagnosis needs to be confirmed by saline infusion sonography (sonohysterography) which separates the two layers of the endometrium or by diagnostic hysteroscopy.

Hysteroscopy is the gold standard for evaluation of the uterine cavity. In addition to direct view, it allows to treat the pathologies diagnosed at the same time. In the present study, $27 \%$ of cases had abnormal uterine cavity during hysteroscopy of which the most frequent pathologies were endometrial polyps, submoucous fibroid and uterine synechiae. Similar to the present study, Shukla et al. (2016) found that the most common uterine pathologies were synechiae $(25.8 \%)$ and polyps (20\%). Koskas et al. (2010) found $40 \%$ of patients with abnormal uterine cavity. ElMazny et al. (2011), found that $33.1 \%$ of patients with uterine pathology, predominantly polyps, submucosal fibroids and uterine synechiae. In the present study, results showed that, in primary infertility patients, the most common uterine pathologies were endometrial polyp, whereas in patients of secondary infertility the most common pathology was uterine synaechie.

Comparing the results between hysteroscopy and TVS showed abnormal findings correctly in $35 \%$ of cases, and $65 \%$ cases were undiagnosed. The TVS was highly specific (100\%), but $79 \%$ sensitive compared with hysteroscopy (sensitivity 95.12\%, specificity 100\%). This was similar to what was found by $E l$ Mazny et al. (2011) where transvaginal ultrasound had a low sensitivity of $41.7 \%$ and a high specificity $100 \%$.

TVS showed that 39 cases $(24.37 \%)$ had intrauterine pathology predominantly fibroids, polyps Via hysteroscopy 57 patients $(35.6 \%)$ were diagnosed. The 
most frequent findings being endometrial polyps. Ragni et al. (2012) evaluated the accuracy of TVS, HSG and hysteroscopy compared to pre IVF patients; found that TVS had a sensitivity of $91 \%$, specificity $83 \%$, PPV of $85.4 \%$ and NPV of $90 \%$.

Hysteroscopy is a valuable, simple, safe, feasible, highly tolerable, sensitive specific, low risk and minimally invasive method which allows an adequate exploration of the uterine cavity under vision and it also provides information about the cervical canal. In patients with infertility, hysteroscopy provides the possibility of immediate diagnosis, prompt and effective treatment. The safety, ease of proficiency and ease of diagnosis, with diagnostic hysteroscopy has taken over much of a guess work out of clinical diagnosis. It is an excellent tool in diagnosis of Asherman's syndrome, Submucous fibroids, and chronic endometritis.

In contrast to our study, Shalev et al. (2010) conclude that because TVS did not miss any of the endometrial abnormalities found later at hysteroscopy, including intrauterine adhesions, endometrial polyps, submucosal myomas, and uterine septae, patients with normal findings on TVS need not undergo further diagnostic workup with hysteroscopy. The use of this protocol reduces not only the number of patients who undergo hysteroscopy but also the morbidity and costs associated with this procedure.

The ability of 2-dimentional sonography to distinguish between different types of uterine abnormalities is limited. Transvaginal 2D sonography is limited in most cases because it cannot produce a coronal image of the uterus to show contour of the outer uterine fundus or the shape of the uterine cavity. 3D-TVS may successfully and adequately overcome the limitations of 2D ultrasound and may improve diagnostic accuracy in the detection of uterine cavity abnormalities. A key advantage of this technique when compared with MRI is the cheaper cost and shorter examination time in experienced hands. Major disadvantages of this technique include the limited availability of the modality as well as the relatively lack of sonographers with adequate training in 3 dimensional image acquisition and post processing techniques (El Tagy et al., 2018).

Diagnostic hysteroscopy especially in an outpatient clinic setting with no anesthesia is superior to two-dimensional TVS in the diagnosis of intrauterine pathology. Office hysteroscopy takes little time with little or no complications in experienced skilled hands. Diagnostic hysteroscopy has a reasonable cost when compared with other radiological examination like three-dimensional TVS or MRI and gives more information than traditional two-dimensional TVS ultrasound (Kandeel et al., 2020).

Hysteroscopy is the most accurate technique in order to visualize the endometrial cavity and diagnose relevant pathologies. Despite the further evolvement of ultrasonography, hysteroscopy provides not only diagnosis but also treatment, when needed. Based on fine hysteroscopy produced recently, hysteroscopy can be easily performed in an office-based environment, not only for diagnostic but also for treatment of minor pathologies. The more attractive office environment compared with the 
conventional operating theater, the noneed for general anaesthesia and the reduced cost compared to the classic hysteroscopy are the main advantages that characterize office hysteroscopy and that made it more popular during the last years (George and Anastasios, 2015).

\section{CONCLUSION}

Diagnostic hysteroscopy was superior to two-dimensional TVS in the diagnosis of intrauterine pathology. Diagnostic hysteroscopy gave more informations than traditional two-dimensional TVS ultrasound. Hysteroscopy did not only provide accurate visual assessment of the uterine cavity, but also provided a chance to treat any pathology detected during the examination.

\section{REFERENCES}

1. Di Spiezio Sardo A, Calagna G, Laganà AS, Vitale SG, Catena U, Scutiero G and Nappi C (2016): Is hysteroscopy better than ultrasonography for uterine cavity evaluation? An evidence-based and patient-oriented approach. Journal of Endometriosis and Pelvic Pain Disorders, $8(3): 87-93$

2. El Tagy P, Hassan A, Abd El Motaal D, Osama A and Awaly D (2018): Comparison between 3D-Transvaginal Ultrasound and Hysteroscopy in Detecting Uterine Cavity Abnormalities. The Egyptian Journal of Hospital Medicine, 73(7):7160-4.

3. Elizabeth $\mathbf{T}$ and Viaor $\mathbf{G}$ (2012): The uterus and fertility. Ferti, Steri., 89: 1-16.

4. El-Mazny A, Abou-Salem N and ElSherbiny W. (2011): Outpatient hysteroscopy: a routine investigation before assisted reproductive techniques? Fertil Steril., 95(1):272-6.
5. George $P$ and Anastasios $M$ (2015): Office Hysteroscopy. Endoscopy: Innovative Uses and Emerging Technologies. Intech Open, 16: 351-359.

6. Gupta JK, Wilson S, Desai P and Hau C (2016): How should we investigate women with postmenopausal bleeding? Acta Obstet Gynecol Scand., 75:475-79.

7. Hajishaiha M, Ghasemi-rad $M$, Karimpour N, Mladkova $\mathbf{N}$ and Boromand F. (2011): Transvaginal sonographic evaluation at different menstrual cycle phases in diagnosis of uterine lesions. Int $\mathrm{J}$ Womens Health, 2011; 3: 353-357.

8. Kandeel MA, Sayyed TM, Tharwat AM and Hamed AS (2020): Hysteroscopy versus transvaginal ultrasound in infertile women prior to intracytoplasmic sperm injection, Menoufia Medical Journal, 33:400-404.

9. Kim SJ and Rhim CC (2014): The value of transvaginal sonography and sonohysterography in the determination of the cause of abnormal uterine bleeding. Journal of Women s Medicine, 2(2):70-6.

10. Koskas M, Mergui JL and Yazbeck C. (2010): Office ysteroscopy for infertility: a series of 557 consecutive cases. Obstet Gynecol Int., 10: 168-174.

11. Kulsum H, Shabnom FC, Maksuda M, Roksana I and Shehnecla T (2010): TVS is the diagnostic method for evaluation of AUB. JSSMC, 2(1): 321326.

12. Loverro G, Nappi L, Vicino $M$, Carriero C, Vimercati $A$ and Selvaggi L (2011): Uterine cavity assessment in infertile women: comparison of transvaginal sonography and hysteroscopy. Eur J Obstet Gynecol Reprod Biol., 100(1):67-71.

13. Niknejadi M, Haghighi H, Ahmadi F, Niknejad F, Chehrazi M, Vosough A 
and Moenian D (2012): Diagnostic Accuracy of Transvaginal Sonography in the Detection of Uterine Abnormalities in Infertile Women, Iran J Radiol., 9(3):139144.

14. Nouri K, Ott J, Huber JC, Fischer EM, Stogbauer $L$ and Tempfer CB (2010): Reproductive outcome after hysteroscopic septoplasty in patients with septate uterus - a retrospective cohort study and systematic review of the literature. Reprod Biol Endocrinol., 8: 52-59.

15. Ragni G, Diaferia D, Vegetti W, Colombo M, Arnoldi $M$ and Crosignani PG (2012): Effectiveness of Sonohysterography in Infertile Patient Work-Up: A Comparison with Transvaginal Ultrasonography and Hysteroscopy Gynecol Obstet Invest., 59:184-188.
16. Shalev J, Meizner I, Bar-Hava I, Dicker $D$, Mashiach $\mathbf{R}$ and Ben-Rafael $Z$ (2010): Predictive value of transvaginal sonography performed before routine diagnostic hysteroscopy for evaluation of infertility. Fertility and Sterility, 73(2):412-7.

17. Shukla $P$, Yadav $K$ and Mishra $S$ (2016): Hysteroscopic evaluation of uterine cavity in cases of infertility and its correlation with transvaginal ultrasound and hysterosalpingography. Int J Reprod Contracept Obstet Gynecol., 5(11):38433848.

18. Soares SR, dos Reis MM and Camargos AF (2010): Diagnostic accuracy of sonohysterography, transvaginal sonography, and hysterosalpingography in patients with uterine cavity diseases. Fertility and Sterility, 73(2):406-11. 
مقارنة بين إستخدام الموجات فوق الصوتية ثنائية الأبعاد عبر

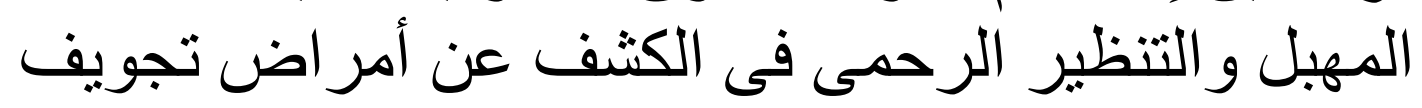

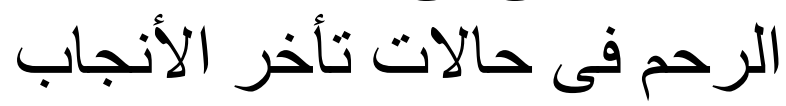

أحمد خليل عبد الثافى، إسماعيل طلعت الجارحى، ماجد محمد لبيب*، أحمد أسامه عبد

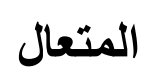

قسم أمراض النساء والتوليد، كلية الطب، جامعة الأزهر

قسم أمر اض النساء والتوليد*، مستثفيات القوات المسلحة

E-mail: drahmedkhali191@gmail.com

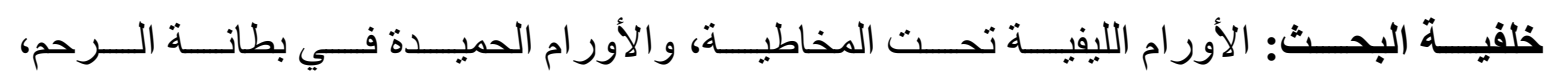

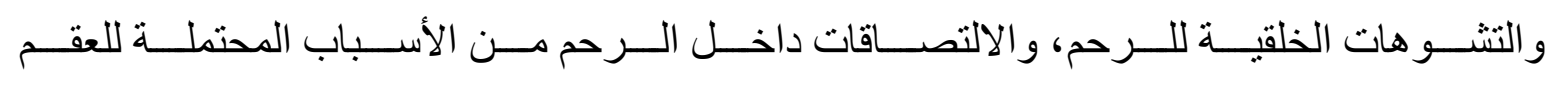

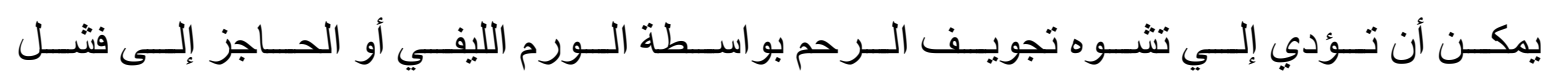

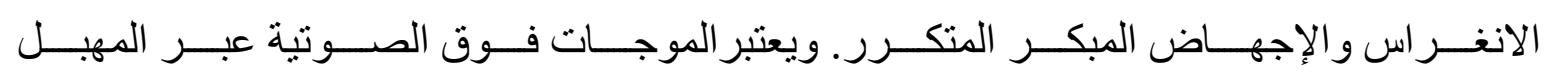

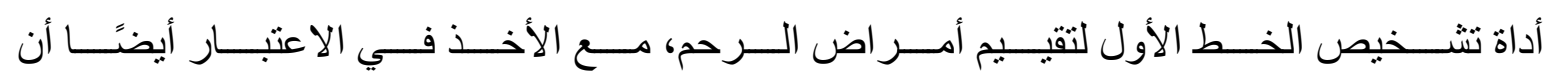

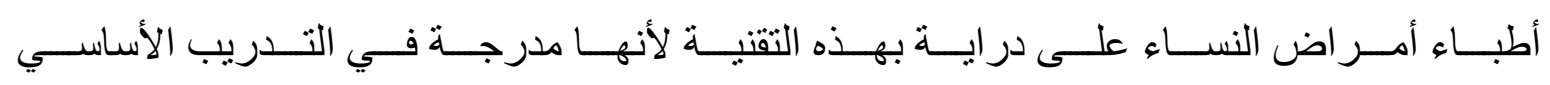

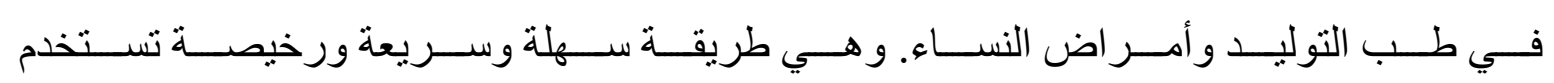

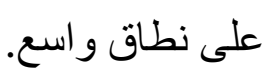

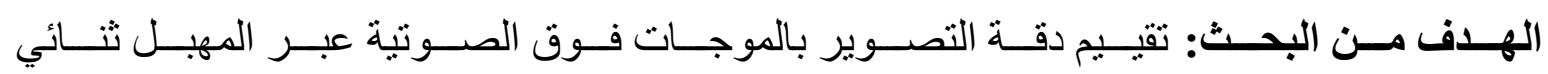

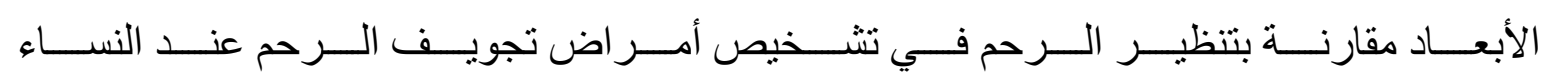

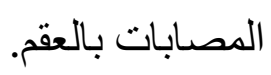

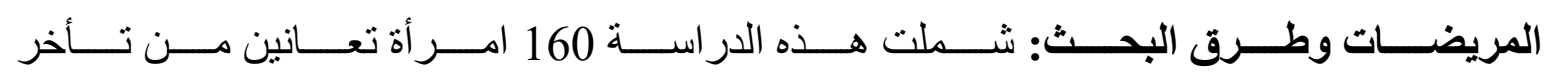

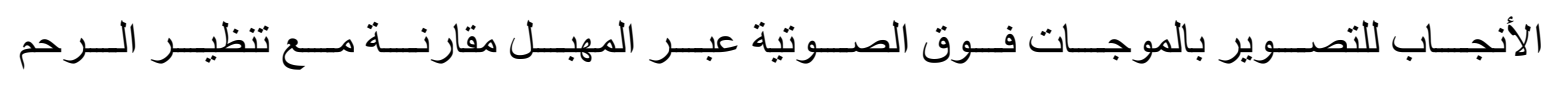

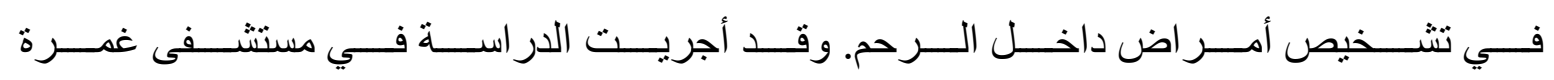

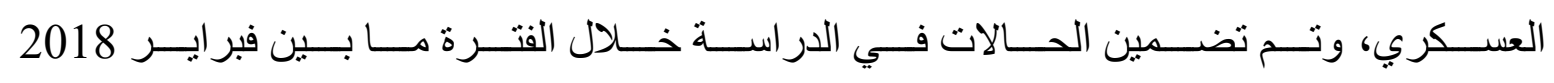

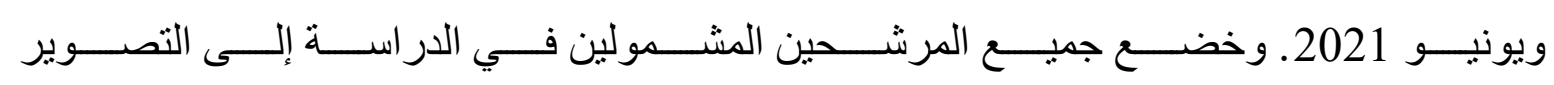

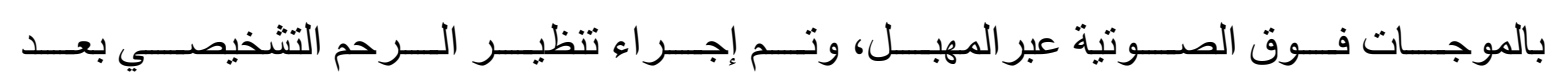




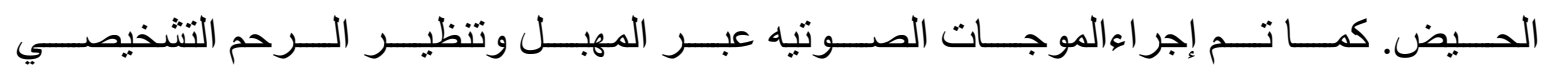
في نفس الدورة.

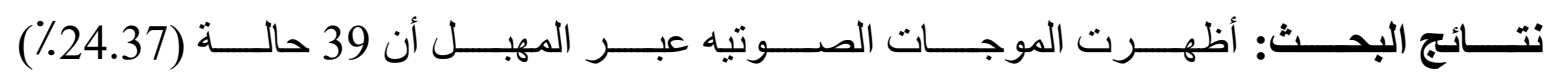

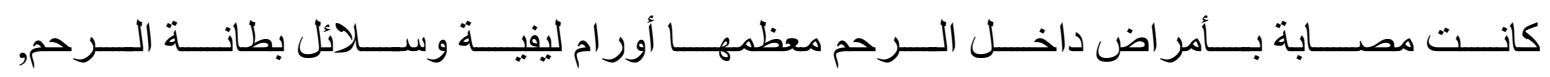

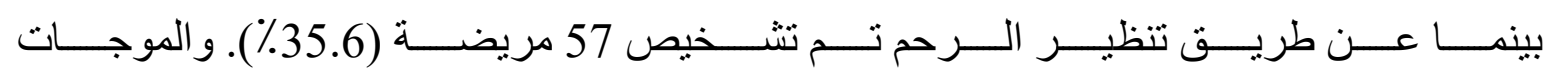

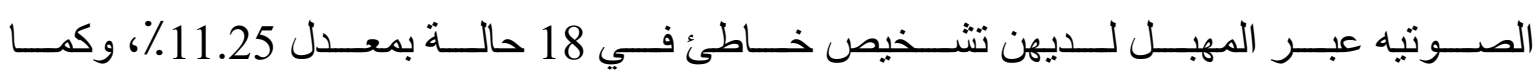

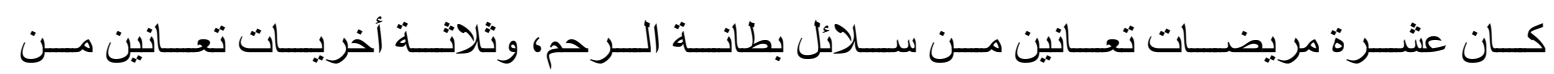

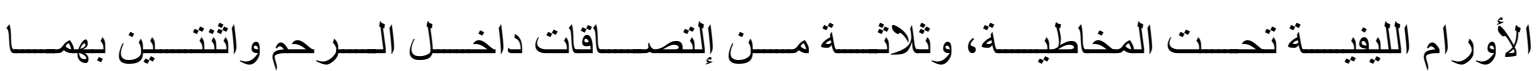
حاجز رحمى.

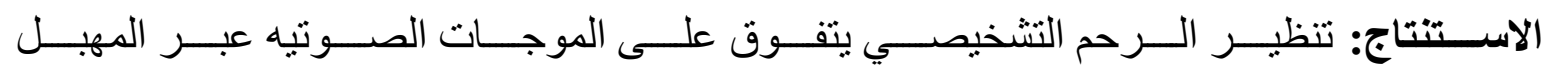

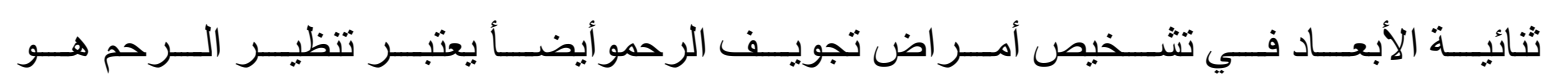

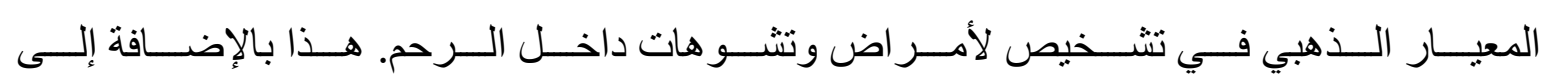
الرؤية المبانرة التي تقدم ميزة كبيرة للتنخل الجراحي و العلاج في نفس الوقت.

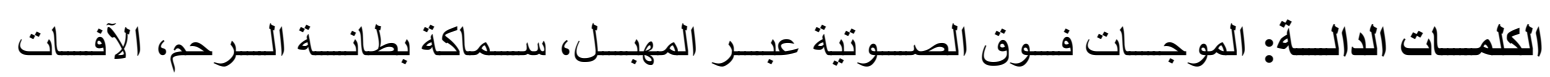

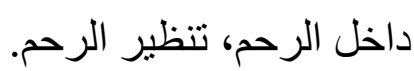

